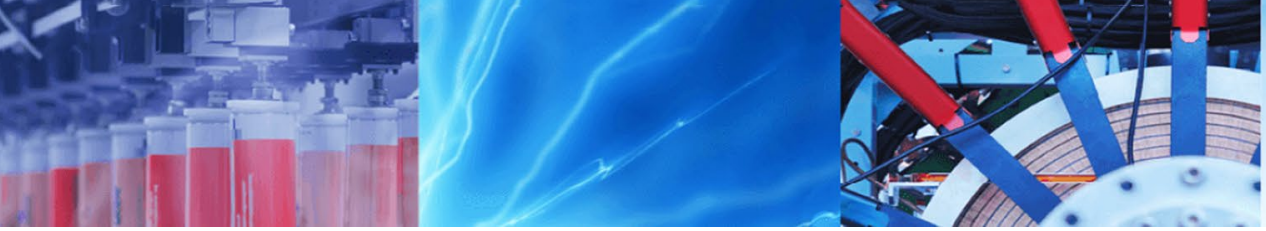

Case Study

\title{
Evaluating and predicting blast-induced ground vibration in open-cast mine using ANN: a case study in Vietnam
}

\author{
Hoang Nguyen ${ }^{1,2}$ (D) Xuan-Nam Bui ${ }^{1,2} \cdot$ Quang-Hieu Tran ${ }^{1,2} \cdot$ Thao-Qui Le $^{1,2} \cdot$ Ngoc-Hoan Do $^{1,3} \cdot$ Le Thi Thu Hoa $^{1}$
}

(c) Springer Nature Switzerland AG 2018

\begin{abstract}
Blasting is one of the cheapest and effective methods for breaking rock mass in open-pit mines. However, its side effects are not small such as ground vibration (PPV), air overpressure, fly rock, back break, dust, and toxic. Of these side effects, blast-induced PPV is the most dangerous for the human and surrounding environment. Therefore, evaluating and accurately forecasting blast-induced PPV is one of the most challenging issues facing open-pit mines today. In this paper, a series of artificial neural network models were applied to predict blast-induced PPV in an open-pit coal mine of Vietnam; 68 blasting events were used in this study for development of the ANN models. Of the whole dataset, 80\% (approximately 56 observations) were used for the training process, and the rest of $20 \%$ (12 observations) were used for the testing process. Five ANN models were developed in this study with the difference in the number of hidden layers. The ANN 2-5-1; ANN 2-8-6-1; ANN 2-5-3-1; ANN 2-8-6-4-1; and ANN 2-10-8-5-1 models were considered in this study. An empirical technique was also conducted to estimate blast-induced PPV and compared to the constructed ANN models. For evaluating the performance of the models, root-mean-squared error (RMSE) and determination coefficient $\left(R^{2}\right)$ were used. The results indicated that the ANN 2-10-8-5-1 model (10 neurons in the first hidden layer, 8 neurons in the second hidden layer, and 5 neurons for the third hidden layer) yielded a superior performance over the other models with an RMSE of 0.738 and $R^{2}$ of 0.964 . In contrast, the empirical performed poorest performance with an RMSE of 2.670 and $R^{2}$ of 0.768 . This study is a new approach to predict blast-induced PPV in open-cast mines aim to minimize the adverse effects of blasting operations on the surrounding environment.
\end{abstract}

Keywords ANN · Machine learning · Blasting · Ground vibration · Open-pit mine

\section{Introduction}

Blasting is one of the cheapest and most effective methods for hard-rock fragmentation in open-pit mines and civil engineering. However, many previous researchers have concluded that only $25-30 \%$ of the explosive energy was directly involved in breaking rock, the rest produces undesirable side effects such as ground vibration (PPV), air overpressure, fly rock, and back break [1-7]. Of these side effects, PPV is the most dangerous side effects for humans and the environment. Therefore, precise prediction of blast-induced PPV is an essential requirement in open-pit mines.

To assess and predict blast-induced PPV, many scientists have access to empirical techniques based on mathematical statistics [8-18]. Empirical techniques were mostly based on mathematical statistical methods and used two input variables including explosive charge per delay/maximum explosive charge capacity $(W)$ and monitoring distance $(R)$. They were considered the two most influential

$\triangle$ Hoang Nguyen, nguyenhoang@humg.edu.vn | ${ }^{1}$ Department of Surface Mining, Hanoi University of Mining and Geology, 18 Vien Street, Duc Thang Ward, Bac Tu Liem District, Hanoi, Vietnam. ${ }^{2}$ Center for Mining, Electro-Mechanical Research, Hanoi University of Mining and Geology, 18 Vien Street, Duc Thang Ward, Bac Tu Liem District, Hanoi, Vietnam. ${ }^{3}$ Faculty of Mining, Saint-Petersburg Mining University, Saint Petersburg, Russia.

SN Applied Sciences (2019) 1:125 | https://doi.org/10.1007/s42452-018-0136-2 
Table 1 Some studies of PPV prediction using soft computational models

\begin{tabular}{llll}
\hline References & Technique & No. of datasets & Performance \\
\hline Monjezi et al. [37] & MLPNN & 269 & $R^{2}=0.954 ; \mathrm{RMSE}=0.03$ \\
Monjezi et al. [38] & ANN & 182 & $R^{2}=0.949$ \\
Armaghani et al. [39] & PSO-ANN & 44 & $R^{2}=0.930 ; \mathrm{MSE}=10.71$ \\
Saadat et al. [21] & ANN & 69 & $R^{2}=0.957 ; \mathrm{MSE}=0.000722$ \\
Hasanipanah et al. [6] & SVM & 80 & $R^{2}=0.957 ; \mathrm{RMSE}=0.340$ \\
Amiri et al. [40] & ANN-KNN & 75 & $R^{2}=0.880 ; \mathrm{RMSE}=0.540$ \\
Hasanipanah et al. [41] & PSO & 80 & $R^{2}=0.938 ; \mathrm{RMSE}=0.240$ \\
Faradonbeh and Monjezi [42] & GEP & 115 & $R^{2}=0.874 ; \mathrm{RMSE}=6.732$ \\
Taheri et al. [23] & ABC-ANN & 89 & $R^{2}=0.920 ; \mathrm{RMSE}=0.220$ \\
Armaghani et al. [43] & ICA & 73 & $R^{2}=0.940 ; \mathrm{RMSE}=0.370$ \\
Behzadafshar et al. [44] & ICA & 76 & $R^{2}=0.939 ; \mathrm{RMSE}=0.320$ \\
Abbaszadeh Shahri and Asheghi [45] & ANN & 37 & $R^{2}=0.954 ; \mathrm{RMSE}=0.157$ \\
Mokfi et al. [46] & GMDH & 102 & $R^{2}=0.911 ; \mathrm{RMSE}=0.889$ \\
Torres et al. [47] & MLR-Empirical & 178 & $R^{2}=0.898$ \\
\hline
\end{tabular}
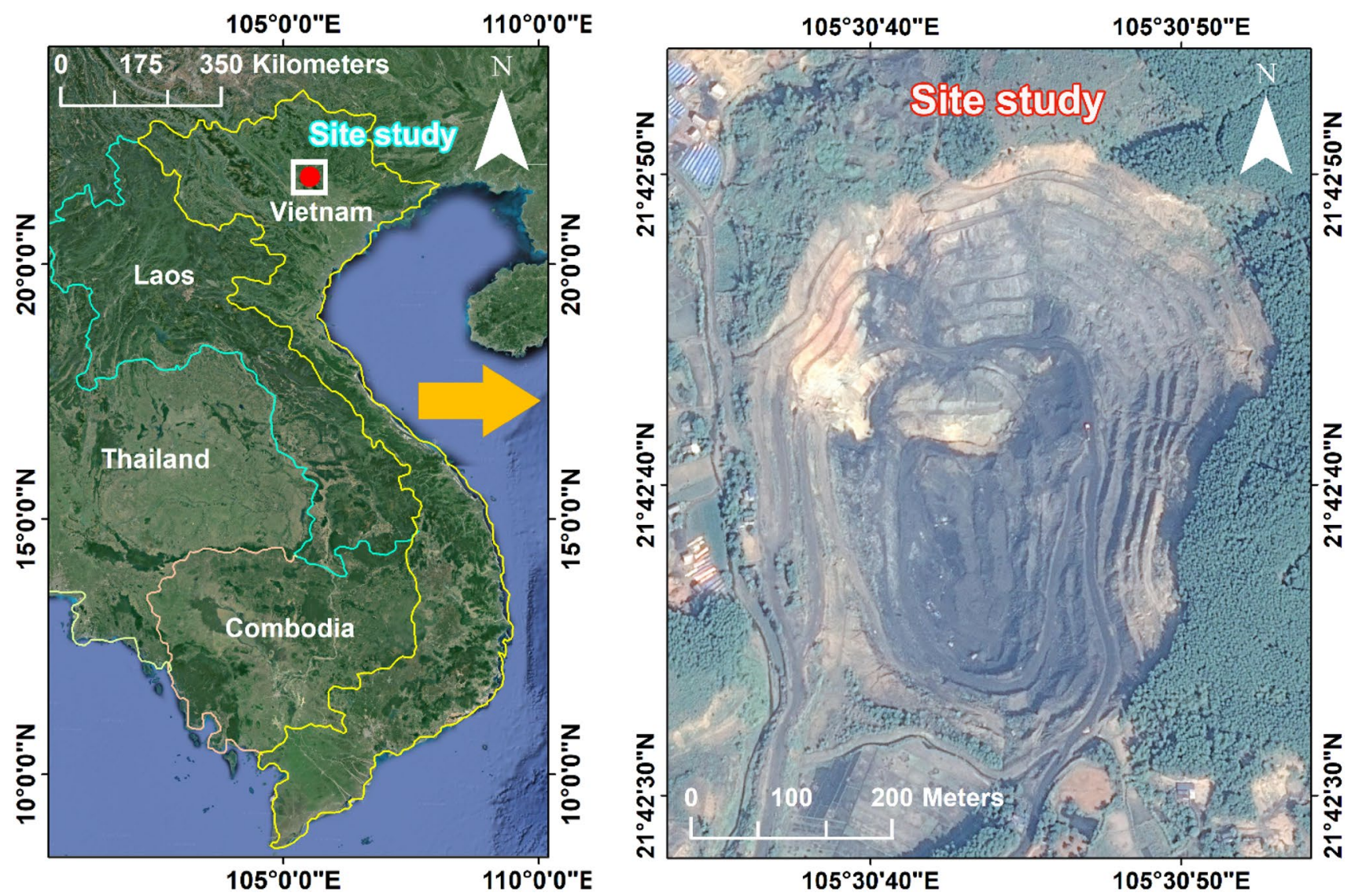

Fig. 1 Overview of the site study

factors for blast-induced PPV [19]. However, their performance was not high in some cases [20-25].
In recent years, various advanced techniques and approaches have been developed to predict and reduce the undesirable effects of blast-induced PPV in open-cast 
Table 2 Characteristic of the datasets used

\begin{tabular}{lll}
\hline$W$ & $R$ & PPV \\
\hline Min.: 136.0 & Min.: 68.0 & Min.: 17.80 \\
1st Qu.: 219.8 & 1st Qu.: 112.0 & 1st Qu.: 24.92 \\
Median: 305.5 & Median: 134.5 & Median: 27.30 \\
Mean: 316.5 & Mean: 131.7 & Mean: 27.47 \\
3rd Qu.: 405.0 & 3rd Qu.: 159.5 & 3rd Qu.: 29.61 \\
Max.: 670.0 & Max.: 204.0 & Max.: 35.63 \\
\hline
\end{tabular}

mining, including machine learning, artificial neural network (ANN), genetic algorithm, fuzzy neural system. Longjun et al. [26] used random forest (RF) and support vector machine (SVM) algorithms to predict blast-induced PPV; 93 blasting events were used for development of the RF and SVM models in their study. Their results showed that the RF and SVM models were acceptable and the SVM model was better than the RF model throughout the PPV predicted values on the testing dataset. Classification and regression tree (CART), multiple regression (MR), and various empirical models were also used by Hasanipanah et al. [27] to predict blast-induced PPV. A total of 86 blasting events were monitored in Miduk copper mine (Iran) for their aim. Hasanipanah et al. [27] concluded that the CART technique exhibited better performance than the empirical and MR models with an RMSE of 0.17 and $R^{2}$ of 0.95 . Chandar et al. [28] examined regression models and ANNs in predicting blast-induced PPV using 168 blasting events in three different mines (limestone, dolomite, and coal). Their results indicated that the ANN model was the best model among the approaches used in their study with a $R^{2}$ of 0.878 for the three mines. Faradonbeh and Monjezi [29] were also successfully developed two robust metaheuristic algorithms to predict blast-induced PPV using 115 blasting events. In their study, a predictive equation based on gene expression programming (GEP) was developed to estimate blast-induced PPV as the first step. Then, the capability of the established GEP model was compared

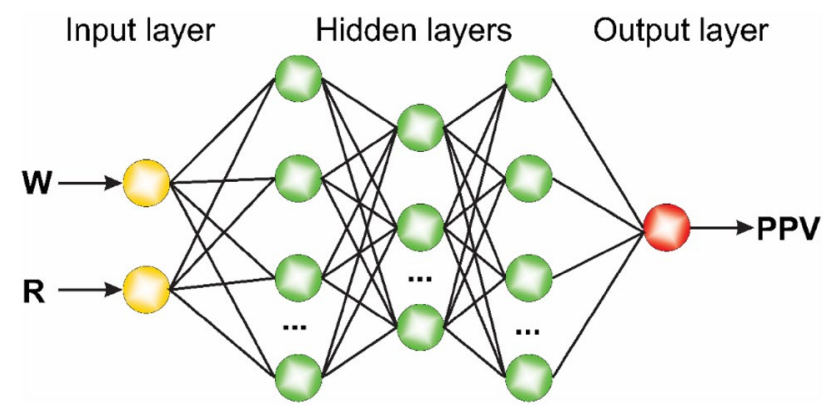

Fig. 2 General structure of an ANN model for predicting blastinduced PPV in this study with that of a nonlinear multiple regression model and five general equations as the next step. Their results revealed that the organized GEP model was more efficient than the other models in predicting blast-induced PPV. In addition, many researchers have used these approaches to predict blast-induced PPV in open-cast mines, and the results were acceptable [22, 23, 30-36]. Table 1 shows several soft computing techniques in predicting blast-induced PPV.

Although the studies of PPV predictions in openpit mines using artificial intelligence (AI) have been approached, no approach or model was optimal for every area. In addition, $\mathrm{Al}$ is an approach that needs to be continually evolving and diverse. Thus, several ANN models for predicting blast-induced PPV at an open-pit mine in Vietnam were developed in this study. The USBM empirical technique was also developed in this study to predict and compare with the ANN technique.

The composition of the article includes four parts: Part 1 reviews a number of published studies and the reasons for this study; Sect. 2 summarizes the data used and the methodology used; the results of this study and discussion are presented in Sect. 3; Finally, the conclusions and recommendations are given in the last section.

\section{Data used and methodologies}

\subsection{Summary of the data used}

As regarding, this research aims to develop an ANN model for predicting blast-produced PPV at an openpit coal mine of Vietnam (Fig. 1). Explosives used at the mine are mainly ANFO with an explosive capacity of $1360-6700 \mathrm{~kg}$. The mine used non-electric delay blasting method for fragmentation of rock. The geological structure of the mine is quite simple. Major components

Table 3 Site factors and empirical equations for predicting PPV in this site study

\begin{tabular}{|c|c|c|c|}
\hline \multirow[t]{2}{*}{ No. } & \multicolumn{2}{|c|}{ Site factors } & \multirow[t]{2}{*}{ Equation } \\
\hline & $k$ & $p$ & \\
\hline 1 & 9.520 & -0.359 & $\mathrm{PPV}=9.520\left(\frac{R}{\sqrt[3]{W}}\right)^{0.359}$ \\
\hline 2 & 6.640 & -0.480 & $\mathrm{PPV}=6.640\left(\frac{R}{\sqrt[3]{W}}\right)^{0.480}$ \\
\hline 3 & 9.427 & -0.362 & $\mathrm{PPV}=9.427\left(\frac{R}{\sqrt[3]{W}}\right)^{0.362}$ \\
\hline 4 & 6.602 & -0.482 & $\mathrm{PPV}=6.602\left(\frac{R}{\sqrt[3]{W}}\right)^{0.482}$ \\
\hline 5 & 9.378 & -0.364 & $\mathrm{PPV}=9.378\left(\frac{R}{\sqrt[3]{W}}\right)^{0.364}$ \\
\hline
\end{tabular}


include clay, siltstone, sandstone, limestone, and coal. Cracks and faults are not present in the study area. The hardness of rock mass is in the range of 8-11 according to the hardness strength of Protodiakonov. Therefore, blasting is an effective method for rock fragmentation in this mine.

In this study, 68 blasting operations were recorded with three parameters: maximum explosive charge per delay $(W)$, monitoring distance $(R)$ and ground vibration (PPV). Of these parameters, $W$ was extracted from 68 blasting designs, and a handheld GPS navigation system was used to determine $R$. In this study, $W$ and $R$ were used as the input variables for predicting PPV. PPV values were measured by Blastmate III, Canada. The datasets used for this study are summarized in Table 2.

Before constructing the forecasting models, a data splitting procedure was performed for this study. Of the 68 observations, $80 \%$ of the whole data ( 56 observations) were used as the training dataset; the remaining 20\% (12 observations) were used as the testing dataset. For the development of the PPV predictive models, the training dataset was used. For evaluating the performance of the models, the testing dataset was used as unseen data based on the developed models.
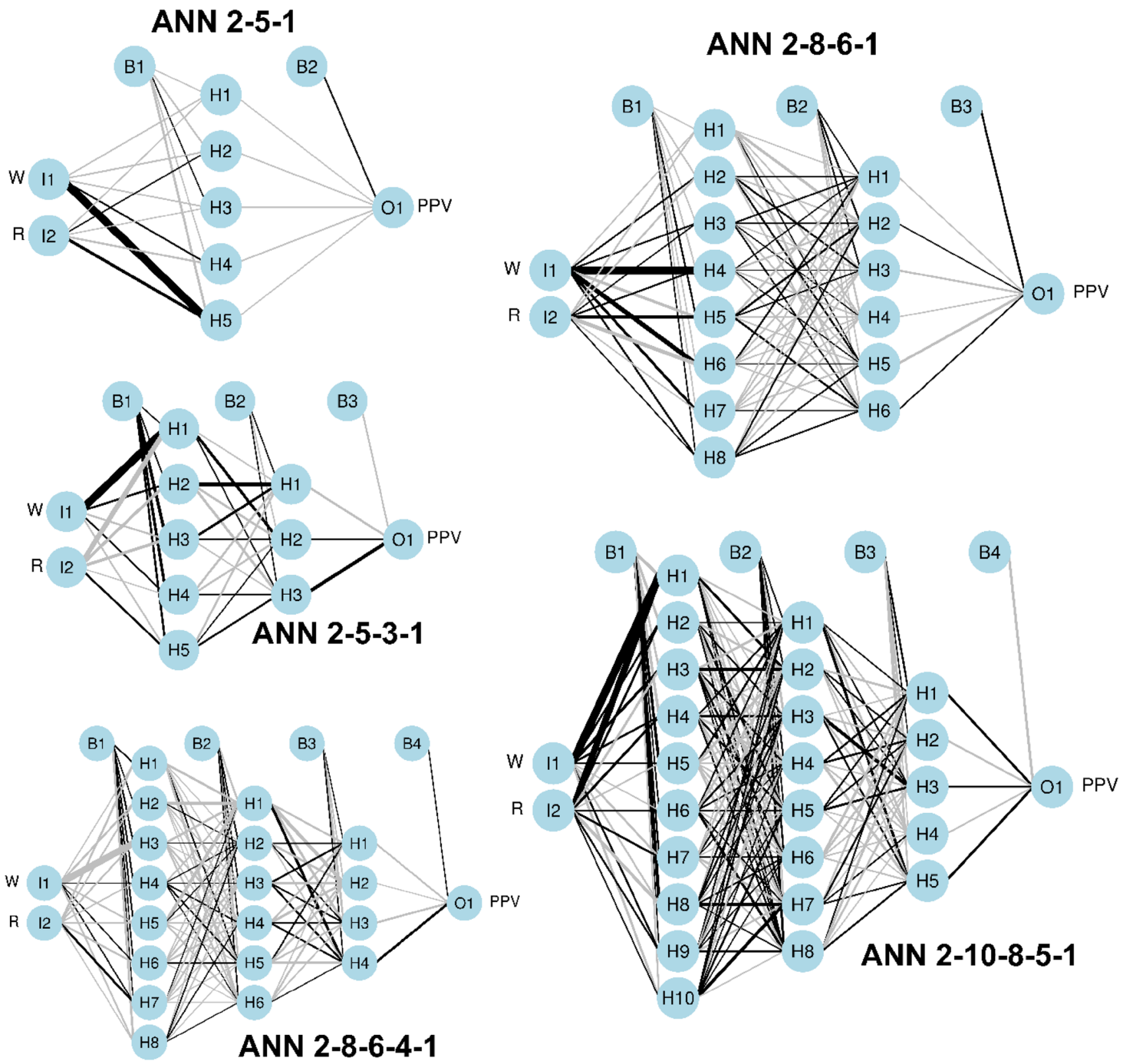

Fig. 3 ANN models for predicting blast-induced PPV in this site study 


\subsection{Empirical technique}

As mentioned in Sect. 1, empirical technique was widely used for predicting blast-induced PPV in open-pit mine [5, 39]. Many scholars have proposed and developed empirical equations for predicting blast-induced PPV [8-18]. Review of the literature showed that the United States Bureau of Mines (USBM) empirical equation was widely applied for estimating blast-induced PPV which was proposed by Duvall and Petkof [8]. However, it was rarely applied in Vietnam. Review of the literature showed that the empirical equation was proposed by Ambraseys [10] which was widely applied in Vietnam [48-50]. Therefore, the empirical equation of Ambraseys [10] was selected representing for an empirical technique to predict blastinduced PPV in this study. It is described as follows:

$\mathrm{PPV}=k\left(\frac{R}{\sqrt[3]{W}}\right)^{-p}$

where $W$ denotes the maximum of charge per delay $(\mathrm{kg})$; $R$ denotes the distance from the blast site $(\mathrm{m}) ; k$ and $p$ are site factors and are determined by multivariate regression analysis.

Table 4 Performance indices of the empirical models

\begin{tabular}{llllll}
\hline \multirow{2}{*}{ No. } & \multicolumn{2}{l}{ Training datasets } & & \multicolumn{2}{c}{ Testing datasets } \\
\cline { 2 - 3 } & RMSE & $R^{2}$ & & RMSE & $R^{2}$ \\
\hline Empirical 1 & 2.480 & 0.603 & & 2.670 & 0.768 \\
Empirical 2 & 2.329 & 0.616 & & 2.814 & 0.677 \\
Empirical 3 & 2.468 & 0.599 & & 2.705 & 0.599 \\
Empirical 4 & 2.266 & 0.618 & & 3.042 & 0.663 \\
Empirical 5 & 2.631 & 0.573 & & 1.823 & 0.761 \\
\hline
\end{tabular}

Table 6 Total rank of the empirical models

\begin{tabular}{llc}
\hline Method & Model no. & Total rank \\
\hline Empirical & $\mathbf{1}$ & $\mathbf{1 4}$ \\
2 & 13 \\
3 & 9 \\
4 & 13 \\
5 & 11 \\
\hline
\end{tabular}

Note: the best empirical model was shown in bold type. It was selected for representing for empirical techniques in this study

\subsection{Overview of ANN}

Artificial neural network (ANN) is one of the most advanced artificial intelligence (AI) techniques that were built based on the human neural structure [51]. They have the ability to connect neurons to solve problems from input signals through the help of computers [51]. The general structure of an ANN consists of three layers: an input layer, hidden layers, and output layer [51]. Figure 2 illustrates a conventional structure of an ANN model for predicting blastinduced PPV in this study. In layers containing neurons with different tasks and functions, the number of hidden layers and neurons in each layer is unlimited. However, too many neurons will lead to overfitting, while too few neurons will not reflect the properties of the data [52]. The number of hidden layers is also one of the factors affecting the training time of the model. In theory, an ANN with two hidden layers can solve all problems. Too many hidden layers will increase the training time of the model.

ANN model works in the following manner: At the input layer, neurons receive input signals with weights. Then, they are processed and sent to the neurons of the first hidden layer via the transfer function. Here, the neurons will receive the results from the input and processing parameter classes, calculate the weights and send them to the second hidden layer via the transfer function. The process
Table 5 Performance indices of the empirical models and their ranking

\begin{tabular}{lllllll}
\hline Method & Model & RMSE & $R^{2}$ & $\begin{array}{l}\text { Rank for } \\
\text { RMSE }\end{array}$ & Rank for $R^{2}$ & Total rank \\
\hline Empirical & Training 1 & 2.48 & 0.603 & 2 & 3 & 5 \\
& Training 2 & 2.329 & 0.616 & 4 & 4 & 8 \\
& Training 3 & 2.468 & 0.599 & 3 & 2 & 5 \\
& Training 4 & 2.266 & 0.618 & 5 & 5 & 10 \\
& Training 5 & 2.631 & 0.573 & 1 & 1 & 2 \\
& Testing 1 & 2.67 & 0.768 & 4 & 5 & 5 \\
& Testing 2 & 2.814 & 0.677 & 2 & 3 & 4 \\
& Testing 3 & 2.705 & 0.599 & 3 & 1 & 3 \\
& Testing 4 & 3.042 & 0.663 & 1 & 2 & 9 \\
\hline
\end{tabular}




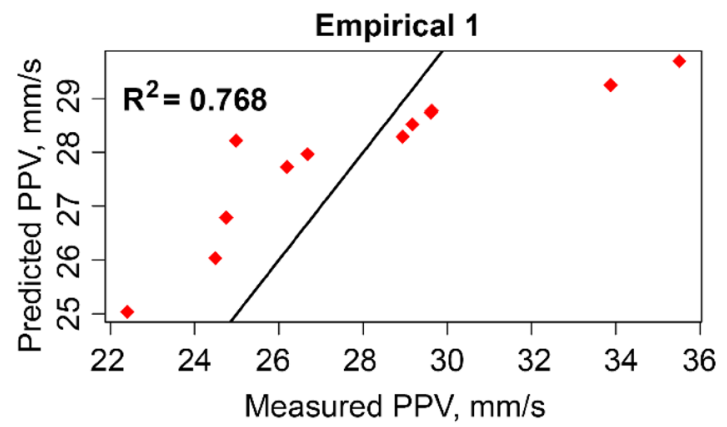

Empirical 2

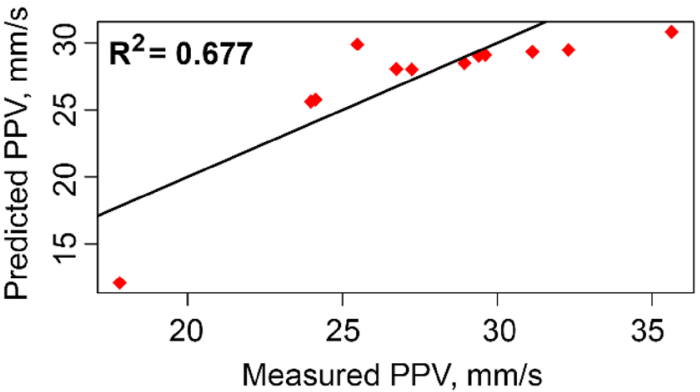

Empirical 4

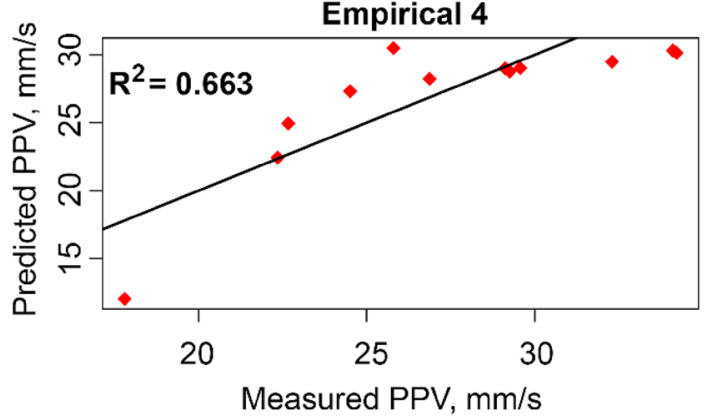

Empirical 3

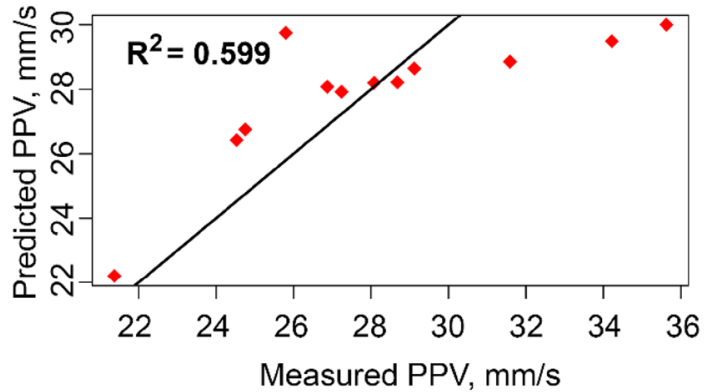

Empirical 5

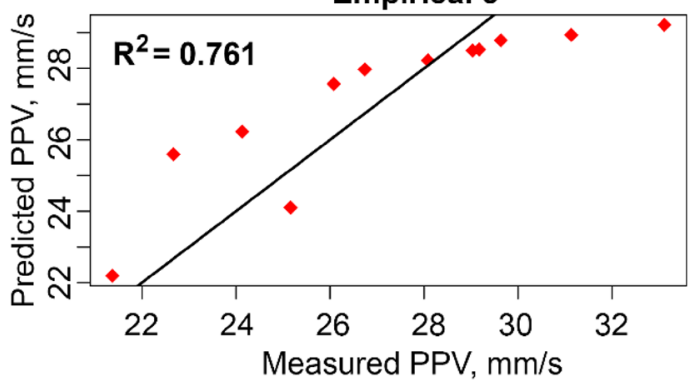

Fig. 4 Predicted and measured PPV in this site study by empirical models

Table 7 Performance indices of the ANN models

\begin{tabular}{llllll}
\hline Model & \multicolumn{2}{l}{ Training datasets } & & \multicolumn{2}{c}{ Testing datasets } \\
\cline { 2 - 3 } & RMSE & $R^{2}$ & & RMSE & $R^{2}$ \\
\hline ANN 2-5-1 & 1.007 & 0.933 & & 1.035 & 0.936 \\
ANN 2-5-3-1 & 0.903 & 0.946 & & 0.831 & 0.958 \\
ANN 2-8-6-1 & 0.842 & 0.953 & & 0.806 & 0.96 \\
ANN 2-8-6-4-1 & 0.856 & 0.952 & & 0.648 & 0.973 \\
ANN 2-10-8-5-1 & 0.821 & 0.956 & & 0.738 & 0.964 \\
\hline
\end{tabular}

continues until the results are passed to the output layer and give the final output [53].

The results of the ANN model depend heavily on the learning process of the network, also known as the training process. The learning process of ANN includes two types of learning: supervised learning and unsupervised learning [54]. Input data for PPV prediction are numerical data and using regression algorithms, so most uses supervised learning based on input data and output requirements.

In this study, five ANN models with one, two, and three hidden layers were considered and developed to predict blast-induced PPV.

\subsection{Establish the predictive models}

For empirical technique, Ambraseys empirical equation was applied according to Eq. (1); 56 blasting events in the training dataset were used for this task. A sampling procedure was repeated five times to create five different sets of data. Then, five empirical models for predicting blastinduced PPV were established. SPSS software version 16.0 [55] was used to analyze multivariate regression data for determining the site factors of $k$ and $p$. The regression 
Table 8 Performance indices of the ANN models and their ranking

\begin{tabular}{lllllll}
\hline Method & Model & RMSE & $R^{2}$ & $\begin{array}{l}\text { Rank for } \\
\text { RMSE }\end{array}$ & Rank for $R^{2}$ & Total rank \\
\hline ANN & Training 1 & 1.007 & 0.933 & 1 & 1 & 2 \\
& Training 2 & 0.903 & 0.946 & 2 & 2 & 4 \\
& Training 3 & 0.842 & 0.953 & 4 & 4 & 8 \\
& Training 4 & 0.856 & 0.952 & 3 & 3 & 6 \\
& Training 5 & 0.821 & 0.956 & 5 & 5 & 10 \\
& Testing 1 & 1.035 & 0.936 & 1 & 1 & 2 \\
& Testing 2 & 0.831 & 0.958 & 2 & 2 & 4 \\
& Testing 3 & 0.806 & 0.96 & 3 & 3 & 10 \\
& Testing 4 & 0.648 & 0.973 & 5 & 5 & 8 \\
\hline
\end{tabular}

Table 9 Total rank of the ANN models

\begin{tabular}{llc}
\hline Method & Model no. & Total rank \\
\hline ANN & 1 & 4 \\
& 2 & 8 \\
& 3 & 14 \\
& 4 & 16 \\
& $\mathbf{5}$ & $\mathbf{1 8}$ \\
\hline
\end{tabular}

Note: the best ANN model was shown in bold type. It was selected for representing for ANN techniques in this study

analysis results and five empirical models are given in Table 3. The performance of the empirical models is discussed in the next section.

For ANN models, a "trial-and-error" procedure with five ANN models was employed to predict blast-induced PPV in this site study. The ANN models with one, two, and three hidden layers were considered and developed in this study. The number of neurons in hidden layers lies in the range of 3-10 to prevent the creation of too complex ANN models; 56 blasting events were used to develop the ANN models for predicting blast-induced PPV in this study. As a result, five ANN models were developed, including ANN 2-5-1; ANN 2-5-3-1; ANN 2-8-6-1; ANN 2-8-6-4-1; and ANN 2-10-8-5-1. The structure of the ANN models is given in Fig. 3.

In Fig. 3, I1 and 12 are input parameters corresponding to $\mathrm{W}$ and $\mathrm{R} ; \mathrm{H} 1$ to $\mathrm{H} 10$ is the number of neurons in each hidden layer; $\mathrm{O} 1$ is the output predicted value (PPV); B1 to $B 4$ are biased layers that apply constant values to the nodes. The black line represents for positive weights, and the gray line represents for negative weights. Line thickness is in proportion to the magnitude of the weight relative to all others.

\section{Results and discussion}

For comparing and evaluating the quality of the predictive models, the performance indices include the root-meansquared error (RMSE) and determination coefficient $\left(R^{2}\right)$ were used in this study and defined by Eqs. (2)-(3) as follows:

$\mathrm{RMSE}=\sqrt{\frac{1}{n} \sum_{i=1}^{n}\left(y_{\mathrm{PPV}}-\hat{y}_{\mathrm{PPV}}\right)^{2}}$

$R^{2}=1-\frac{\sum_{i}\left(y_{\mathrm{PPV}}-\hat{y}_{\mathrm{PPV}}\right)^{2}}{\sum_{i}\left(y_{\mathrm{PPV}}-\bar{y}\right)^{2}}$

where $n$ is the total number of data. $y_{\mathrm{PPV}}, \hat{y}_{\mathrm{PPV}}$ and $\bar{y}$ are the measured, predicted and mean of the $y_{\mathrm{PPV}}$ values, respectively.

\subsection{Empirical models}

Based on the empirical models developed in Table 3, the RMSE and $R^{2}$ performance indicators were calculated according to Eqs. (2) and (3) for training dataset and testing dataset. The performance of the empirical models is shown in Table 4.

From Table 4, it can be seen that the empirical models for predicting blast-induced PPV in this study are not so bad. However, it is difficult to assess which empirical model is the best among the five empirical models developed. Therefore, a simple ranking method was applied in this study to find the optimal empirical model. The ranking results for the empirical models are shown in Table 5. Also, a total ranking on both training and testing datasets is also presented in Table 6.

Based on Table 6, it is effortless to see that the empirical model No.1 was the best empirical model for predicting blast-induced PPV in this study with a total ranking of 14 . 


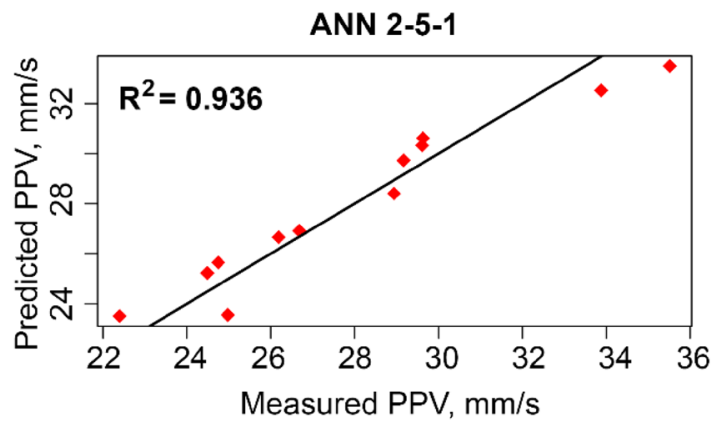

ANN 2-5-3-1

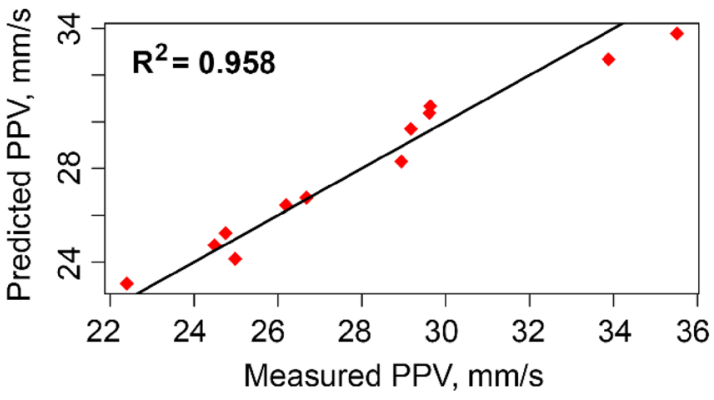

ANN 2-8-6-4-1

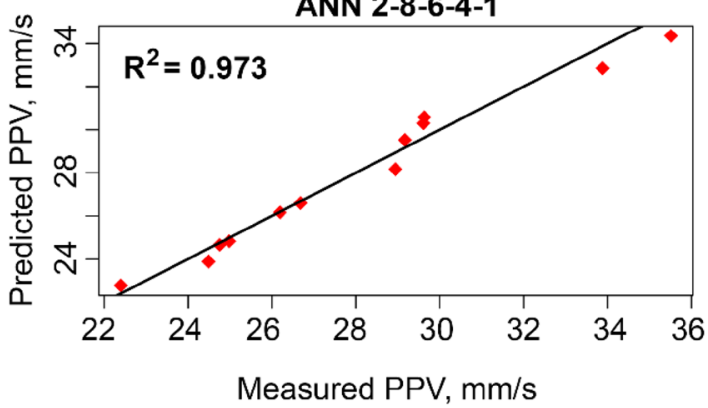

ANN 2-8-6-1

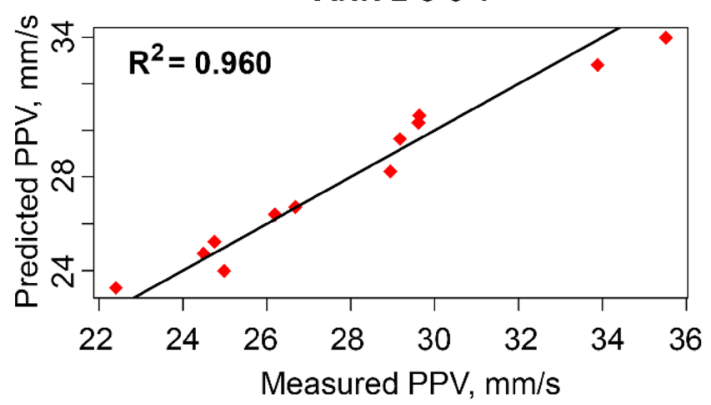

ANN 2-10-8-5-1

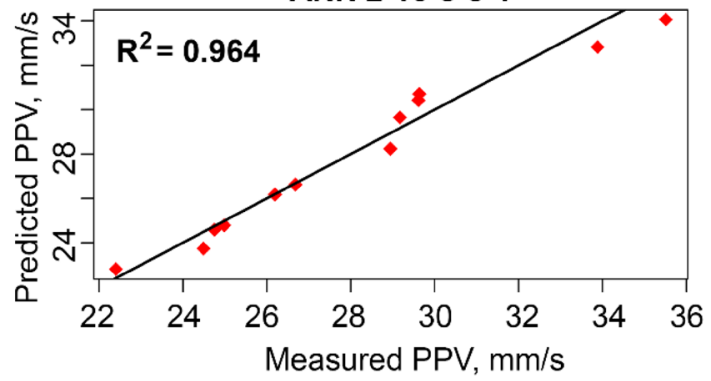

Fig. 5 Measured versus predicted PPV in this study by the ANN models

Table 10 Comparisons of performance between the empirical and ANN selected

\begin{tabular}{llllll}
\hline Method & \multicolumn{2}{l}{ Training datasets } & & \multicolumn{2}{l}{ Testing datasets } \\
\cline { 2 - 3 } & RMSE & $R^{2}$ & & RMSE & $R^{2}$ \\
\hline Empirical & 2.480 & 0.603 & & 2.670 & 0.768 \\
ANN & 0.821 & 0.956 & & 0.738 & 0.964 \\
\hline
\end{tabular}

The empirical models No. 2 and No. 4 were also performed well in this study with a slightly lower performance than empirical model No. 1. In addition, it can be seen that empirical model No. 3 provided the poorest performance in this study with a total ranking of 9 . Figure 4 illustrates the relationship between measured and predicted values by the empirical models in this study.

\subsection{The ANN models}

In this section, the performance of the ANN models was highlighted. Accordingly, five ANN models are developed in Sect. 2.4: ANN 2-5-1; ANN 2-5-3-1; ANN 2-8-6-1; ANN 2-8-6-4-1; and ANN 2-10-8-5-1. For each ANN model, performance indices were computed using Eqs. (2)-(3). Note that the training and testing datasets of these ANN models are the same. The performance of the ANN models is shown in Table 7.

From Table 7, it can be seen that the ANN models worked better than the empirical models in predicting blast-induced PPV in this study. However, it is difficult to select the most optimal ANN model among the five ANN models developed. Thus, a simple ranking method was also applied to find out the optimal ANN model in this case. Table 8 interprets the performance of the ANN models and their ranking on both the training and testing datasets. Table 9 summarizes the ranking of each ANN model. 
Fig. 6 A comparison of predicted values by empirical and ANN models

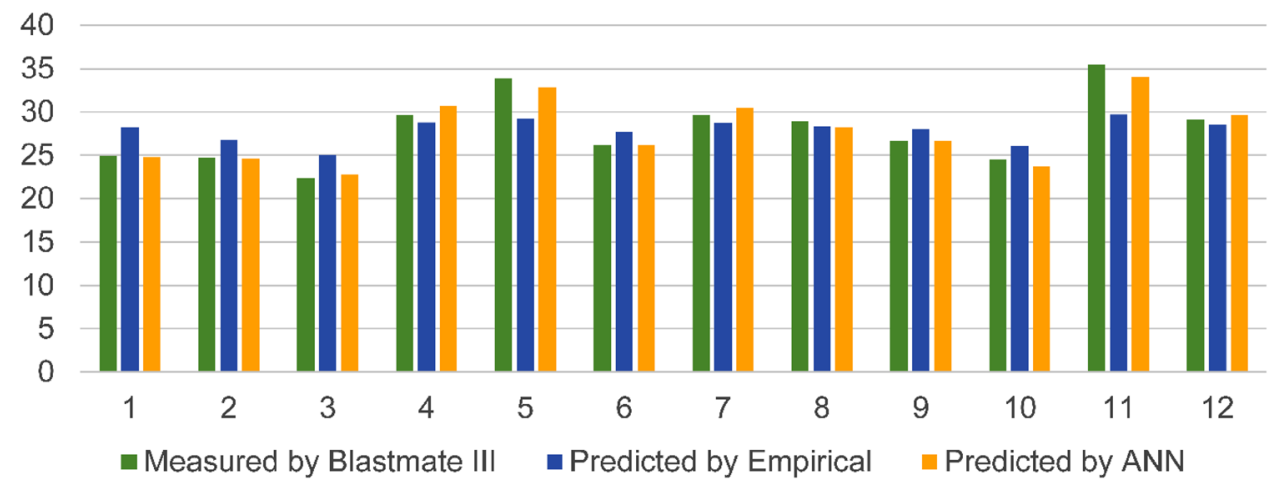

Based on Table 9, it is easy to see that the ANN model No. 5 (2-10-8-5-1) provided the best performance with a total ranking of 18 . The ANN model No. 4 (2-8-6-4-1) was also useful for predicting PPV with slightly lower performance than the ANN model No. 5 . Table 9 shows that the ANN model with one hidden layer (2-5-1) yielded the poorest performance among 5 ANN models used in this study. Figure 5 illustrates the relationship between the measured and predicted values by the ANN models in this study.

\subsection{Performance evaluation between the ANN model and empirical model}

Based on the above results, two PPV predictive models were selected: the empirical model No. 1 representing for empirical technique, and the ANN 2-10-8-5-1 model representing for ANN technique in this study. A comparison and evaluation between the empirical model and the ANN model are given in Table 10. As a result, the selected ANN model obtained a better performance than the selected empirical model based on RMSE and $R^{2}$. Figure 6 shows that the PPV predicted values by the ANN model were closer to actual values than the empirical model.

\section{Conclusion and remarks}

Blasting is an integral part of the open-pit mining technology. However, its side effects are dangerous for the surrounding environment, especially ground vibration (PPV). Therefore, accurate prediction of blast-induced PPV is essential to minimize the undesirable effects caused by PPV. From the results of this study, we draw some conclusions:

- ANN is an advanced and robust technique that should be used to predict blast-induced PPV in open-pit mines. This study has developed a robust ANN model with high accuracy (RMSE $\left.=0.738, R^{2}=0.964\right)$. It should be applied in practical engineering to control the undesirable effects on the surrounding environment. However, the development of the ANN models in open-pit mine is often complicated, requiring the user to have an understanding of mathematics and programming.

- The ANN model with a hidden layer should not be used to predict PPVs because it does not reflect all the characteristics of the data that lead to the inaccuracy of the forecasting model. The ANN model with three hidden layers has been proposed for predicting blast-induced PPV in practical engineering based on the results of this study. ANN models with many hidden layers should be considered in the future for predicting blast-induced PPV.

- The empirical technique is a rapid and straightforward method of estimating blast-induced PPV, but further research is needed to improve the accuracy of empirical models.

- The other influence parameters should be considered and supplemented to improve the accuracy of PPV predictive models, especially for empirical methods.

The results of this study are the basis for the development of blast-induced PPV predictive models for other open-pit mines with similar conditions. At the same time, it is useful for managers, engineers, and blasters in optimizing blasting efficiency and minimizing the negative impacts caused by blasting operations in open-pit mines.

Acknowledgements We thank Hanoi University of Mining and Geology (HUMG), and the Center for Mining, Electro-Mechanical research of HUMG.

\section{Compliance with ethical standards}

Conflict of interest The author declares that there is no conflict of interests regarding the publication of this paper. 


\section{References}

1. Khandelwal M, Singh T (2005) Prediction of blast induced air overpressure in opencast mine. Noise Vib Worldw 36(2):7-16

2. Khandelwal M, Singh T (2009) Prediction of blast-induced ground vibration using artificial neural network. Int J Rock Mech Min Sci 46(7):1214-1222

3. Verma A, Singh T (2011) Intelligent systems for ground vibration measurement: a comparative study. Eng Comput 27(3):225-233

4. Monjezi M, Khoshalan HA, Varjani AY (2012) Prediction of flyrock and backbreak in open pit blasting operation: a neuro-genetic approach. Arab J Geosci 5(3):441-448

5. Monjezi M, Hasanipanah M, Khandelwal M (2013) Evaluation and prediction of blast-induced ground vibration at Shur River Dam, Iran, by artificial neural network. Neural Comput Appl 22(7-8):1637-1643

6. Hasanipanah M, Monjezi M, Shahnazar A, Armaghani DJ, Farazmand A (2015) Feasibility of indirect determination of blast induced ground vibration based on support vector machine. Measurement 75:289-297

7. Hasanipanah M, Shahnazar A, Amnieh HB, Armaghani DJ (2017) Prediction of air-overpressure caused by mine blasting using a new hybrid PSO-SVR model. Eng Comput 33(1):23-31

8. Duvall WI, Petkof B (1958) Spherical propagation of explosiongenerated strain pulses in rock. Bureau of Mines. Report of Investigations 5483. US Department of the Interior, Bureau of Mines, Washington, DC

9. Langefors U, Kihlstrom B (1963) The modern techniques of rock blasting. Wiley, New York

10. Ambraseys NN, Hendron AJ (1968). In: Stagg KG, Zienkiewicz OC (eds) Rock mechanics in engineering practice. Wiley, London

11. Standard I (1973) Criteria for safety and design of structures subjected to underground blast. ISI, IS-6922

12. Ghosh A, Daemen JJ (1983) A simple new blast vibration predictor (based on wave propagation laws). In: The 24th US symposium on rock mechanics (USRMS). American Rock Mechanics Association

13. Roy PP (1991) Vibration control in an opencast mine based on improved blast vibration predictors. Min Sci Technol 12(2):157-165

14. Murmu S, Maheshwari P, Verma HK (2018) Empirical and probabilistic analysis of blast-induced ground vibrations. Int J Rock Mech Min Sci 103:267-274

15. Rai R, Singh T (2004) A new predictor for ground vibration prediction and its comparison with other predictors. Indian J Eng Mater Sci 11:178-184

16. Ak H, Konuk A (2008) The effect of discontinuity frequency on ground vibrations produced from bench blasting: a case study. Soil Dyn Earthq Eng 28(9):686-694

17. Simangunsong GM, Wahyudi S (2015) Effect of bedding plane on prediction blast-induced ground vibration in open pit coal mines. Int J Rock Mech Min Sci 79:1-8

18. Kumar R, Choudhury D, Bhargava K (2016) Determination of blast-induced ground vibration equations for rocks using mechanical and geological properties. J Rock Mech Geotechn Eng 8(3):341-349

19. Siskind DE, Stachura VJ, Stagg MS, Kopp JW (1980) Structure response and damage produced by airblast from surface mining. Bureau of Mines. Report of Investigations 8485. US Department of the Interior, Bureau of Mines, Washington, DC

20. Monjezi Ghafurikalajahi M, Bahrami A (2011) Prediction of blast-induced ground vibration using artificial neural networks. Tunn Undergr Space Technol 26(1):46-50
21. Saadat M, Khandelwal M, Monjezi M (2014) An ANN-based approach to predict blast-induced ground vibration of GolE-Gohar iron ore mine, Iran. J Rock Mech Geotechn Eng 6(1):67-76

22. Sheykhi H, Bagherpour R, Ghasemi E, Kalhori H (2017) Forecasting ground vibration due to rock blasting: a hybrid intelligent approach using support vector regression and fuzzy C-means clustering. Eng Comput 34(2):357-365. https://doi. org/10.1007/s00366-017-0546-6

23. Taheri K, Hasanipanah M, Golzar SB, Majid MZA (2017) A hybrid artificial bee colony algorithm-artificial neural network for forecasting the blast-produced ground vibration. Eng Comput 33(3):689-700

24. Nguyen H, Bui X-N (2018) A comparison of artificial neural network and empirical technique for predicting blast-induced ground vibration in open-pit mine. In: Mining sciences and technology-XXVI, Mong Cai, Hanoi, Vietnam. Industry and Trade of the Socialist Republic of Vietnam, pp 177-182

25. Nguyen H, Bui X-N, Thanh NT, Anh NT (2018) Effectiveness comparison between linear regression and non-linear regression algorithms in predicting blast-induced ground vibration in Nui Beo open-pit coal mine-Quang Ninh. J Min Ind 02:24-27

26. Longjun D, Xibing L, Ming X, Qiyue L (2011) Comparisons of random forest and support vector machine for predicting blasting vibration characteristic parameters. Procedia Eng 26:1772-1781

27. Hasanipanah M, Faradonbeh RS, Amnieh HB, Armaghani DJ, Monjezi M (2017) Forecasting blast-induced ground vibration developing a CART model. Eng Comput 33(2):307-316

28. Chandar KR, Sastry V, Hegde C (2017) A critical comparison of regression models and artificial neural networks to predict ground vibrations. Geotech Geol Eng 35(2):573-583

29. Faradonbeh RS, Monjezi M (2017) Prediction and minimization of blast-induced ground vibration using two robust metaheuristic algorithms. Eng Comput 33(4):835-851. https://doi. org/10.1007/s00366-017-0501-6

30. Faradonbeh RS, Armaghani DJ, Majid MA, Tahir MM, Murlidhar $\mathrm{BR}$, Monjezi $\mathrm{M}$, Wong $\mathrm{H}$ (2016) Prediction of ground vibration due to quarry blasting based on gene expression programming: a new model for peak particle velocity prediction. Int J Environ Sci Technol 13(6):1453-1464

31. Hasanipanah M, Golzar SB, Larki IA, Maryaki MY, Ghahremanians T (2017) Estimation of blast-induced ground vibration through a soft computing framework. Eng Comput 33(4):951959. https://doi.org/10.1007/s00366-017-0508-z

32. Hajihassani M, Armaghani DJ, Marto A, Mohamad ET (2015) Ground vibration prediction in quarry blasting through an artificial neural network optimized by imperialist competitive algorithm. Bull Eng Geol Env 74(3):873-886

33. Armaghani DJ, Momeni E, Abad SVANK, Khandelwal M (2015) Feasibility of ANFIS model for prediction of ground vibrations resulting from quarry blasting. Environ Earth Sci 74(4):2845-2860

34. Monjezi M, Baghestani M, Faradonbeh RS, Saghand MP, Armaghani DJ (2016) Modification and prediction of blast-induced ground vibrations based on both empirical and computational techniques. Eng Comput 32(4):717-728

35. Ghoraba S, Monjezi M, Talebi N, Armaghani DJ, Moghaddam M (2016) Estimation of ground vibration produced by blasting operations through intelligent and empirical models. Environ Earth Sci 75(15): 1137

36. Mohamad ET, Noorani SA, Armaghani DJ, Saad R (2012) Simulation of blasting induced ground vibration by using artificial neural network. Electron J Geotech Eng 17:2571-2584

37. Monjezi M, Ahmadi M, Sheikhan M, Bahrami A, Salimi A (2010) Predicting blast-induced ground vibration using various types of neural networks. Soil Dyn Earthq Eng 30(11):1233-1236 
38. Monjezi M, Ghafurikalajahi M, Bahrami A (2011) Prediction of blast-induced ground vibration using artificial neural networks. Tunn Undergr Space Technol 26(1):46-50

39. Armaghani DJ, Hajihassani M, Mohamad ET, Marto A, Noorani $S$ (2014) Blasting-induced flyrock and ground vibration prediction through an expert artificial neural network based on particle swarm optimization. Arab J Geosci 7(12):5383-5396

40. Amiri M, Amnieh HB, Hasanipanah M, Khanli LM (2016) A new combination of artificial neural network and K-nearest neighbors models to predict blast-induced ground vibration and air-overpressure. Eng Comput 32(4):631-644

41. Hasanipanah M, Naderi R, Kashir J, Noorani SA, Qaleh AZA (2017) Prediction of blast-produced ground vibration using particle swarm optimization. Eng Comput 33(2):173-179

42. Faradonbeh RS, Monjezi M (2017) Prediction and minimization of blast-induced ground vibration using two robust metaheuristic algorithms. Eng Comput 33(4):835-851

43. Armaghani DJ, Hasanipanah M, Amnieh HB, Mohamad ET (2018) Feasibility of ICA in approximating ground vibration resulting from mine blasting. Neural Comput Appl 29(9):457-465

44. Behzadafshar K, Mohebbi F, Soltani Tehrani M, Hasanipanah M, Tabrizi O (2018) Predicting the ground vibration induced by mine blasting using imperialist competitive algorithm. Eng Comput 35(4):1774-1787

45. Abbaszadeh Shahri A, Asheghi R (2018) Optimized developed artificial neural network-based models to predict the blastinduced ground vibration. Innov Infrastruct Solut 3:1-10

46. Mokfi T, Shahnazar A, Bakhshayeshi I, Derakhsh AM, Tabrizi O (2018) Proposing of a new soft computing-based model to predict peak particle velocity induced by blasting. Eng Comput 34(4):881-888. https://doi.org/10.1007/s00366-018-0578-6

47. Torres VN, Silveira LG, Lopes PF, de Lima HM (2018) Assessing and controlling of bench blasting-induced vibrations to minimize impacts to a neighboring community. J Clean Prod 187:514-524

48. Bach NV, Thanh NV (1996) The effects of blasting operations in the surrounding structures. J Min Ind 4:13-14 (in Vietnamese)

49. Bach NV, Quyen LV, Nam BX, An ND, Phuc NV (2006) Reducing the undesirable effects of blast-induced ground vibration in Nui Beo open-pit coal mine. J Sci Technol Hanoi Univ Min Geol 14:58-62 (in Vietnamese)

50. Bach NV, Nam BX, An ND, Hung TK (2012) Determination of blast-induced ground vibration for non-electric delay blasting. J Sci Technol Hanoi Univ Min Geol 38:25-28 (in Vietnamese)

51. Schalkoff RJ (1997) Artificial neural networks, vol 1. McGraw-Hill, New York

52. Nguyen $\mathrm{H}$, Bui X-N, Bui H-B, Mai N-L (2018) A comparative study of artificial neural networks in predicting blast-induced air-blast overpressure at Deo Nai open-pit coal mine, Vietnam. Neural Comput Appl. https://doi.org/10.1007/s00521-018-3717-5

53. Zerguine A, Shafi A, Bettayeb M (2001) Multilayer perceptron-based DFE with lattice structure. IEEE Trans Neural Netw 12(3):532-545

54. Perez LG, Flechsig AJ, Meador JL, Obradovic Z (1994) Training an artificial neural network to discriminate between magnetizing inrush and internal faults. IEEE Trans Power Deliv 9(1):434-441

55. Norusis M (2008) SPSS 16.0 advanced statistical procedures companion. Prentice Hall Press, Upper Saddle River 